\title{
LITERARY THEORY: \\ INTRODUCTION AND GREEK ORIGINS
}

José Angel García Landa

University of Zaragoza

http://www.garcialanda.net

\section{An Introduction to Literary Theory}

This paper presents the prolegomena to a historical approach to literary theory and literary criticism. We shall call "literary theory" the discipline which studies in a formal way the characteristics of literary texts and other aspects of the literary phenomenon, in themselves or as they relate to other aspects of culture. Literary theory tries to formulate general laws and principles: it is not concerned with the consideration or evaluation of particular works of literature. Of course, a literary theory, whether explicit or implied, underlies any specific study or evaluation of a particular literary work. This study or evaluation of particular literary works is what we call criticism. Therefore, literary criticism presupposes literary theory. Very often, the two concepts are included in the term "criticism," but here we shall attempt to preserve this conceptual difference. The difference between literary theory and literary criticism is a conceptual one - in practice, it may be more or less clear-cut, and so we can speak of the literary theory of a critic who only wrote on particular works.

$\begin{array}{lll}\text { Literary theory } & \text { Literary criticism } & \text { Literary history } \\ \text { Philosophy } & \text { Applied interpretation } & \text { Cultural and political } \\ \text { Aesthetics } & \text { Analysis } & \text { history } \\ \text { Ethics } & \text { Comparison } & \\ \text { Hermeneutics } & \text { Commentary } & \\ \text { Politics } & \text { Explication } & \\ \text { Science } & \\ \text { Psychology } & \\ \text { Sociology } & \\ \text { Anthropology } & \\ \text { Linguistics } & \\ \text { Semiotics } & \\ \text { Theory of } & \\ \text { culture and history } & \\ \text { Religion } & \end{array}$

A theory of literature may also be said to underlie the discipline of literary history. The study of the historical development of literature may seem at first sight to be more objective than the criticism of a given work, even though it generally includes criticism as well as mere factual information about literature. But even the more "objective" data are submitted to a theory of literature, which determines which facts relative to 
the works, the autors or the social context are thought relevant to be included in such a history of literature (Batman? Agatha Christie?). But literary history and literary theory as such are obviously different undertakings. And there can be a history of literary theory (with its own assumptions or underlying literary theory) just as there is a history of literature.

Our aim is to study the development of the conceptual apparatus of literary theory, and its practical application in criticism. We are not going to deal with different, alternative approaches to the literary work as if all were equivalent, or to map the territory of literary theory in its present state. We are not going to deal with the development of literature, either. Sometimes the literature of an era and its literary theory are widely apart: for instance, there were no successful epics written during the eighteenth century, and the novel was the most popular genre. But the literary theory of the time completely ignores the novel and places the epic foremost in its evaluative schemes. The best theoretical formulations of the conceit of seventeenth-century poetry are found in the eighteenth century. In studying literary criticism we will point out some aspects of the distance between theory and praxis, but in the main we will take for granted a knowledge of the history of literature, and will concentrate on the conceptual development of the discipline of literary theory. For instance, in studying classical literary theory we will not be concerned with the different role of, say, prophecies in Homer and Virgil. From our present vantage point we may see a different role fulfilled by prophecies in the epics of each author, but this was not a difference which was paid attention to by Roman literary theory--it is a development of our own theory of literature, not Virgil's. We are concerned only with actual theoretical pronouncements on the subject of literature, and not with any literary manifestation which may be linked to them. This may seem too abstract, but literary theory is an abstractive discipline: it tries to discover certain patterns in literature and in literary history by means of an abstractive process. And in doing so, it creates its own pattern of historical development. Our ideas about literary history are not the same as those of the Romantics.

History is, of course, a continuous process, but we may find it useful to establish some internal division into periods in order to approach our subject, literary criticism, in an amenable way. One possible criterion is to apply to the history of literary criticism those general divisions which we are already acquainted with in other areas of historical study. We would have then classical literary criticism, which could be divided into Greek and Roman; medieval criticism, renaissance and neoclassical criticism, Romantic criticism, and then the apparent chaos of modern critical theories. We will follow here this type of classification, but we will also try to discover any characteristics that oppose one period to the other in terms that are internal to the discipline of literary criticism itself. In this respect, it may be useful to provide from the start some guiding principle to have some hold of our own on the discipline before attempting an approach to the origins of literary criticism. 
We may find such a principle in the more general discipline of semiotics. Literature is in its surface a linguistic phenomenon, in that apparently its raw material is words and nothing but words. But this is a deceptive appearance. Words are tools used in a specific code, language, to create meaning. But "meaning" is not the final result of the process, at least not in such a simple, unanalysed form. Meaning can be analysed, because the linguistic code relies on and works together with many other codes and conventions which are not linguistic. For instance, in American thriller films of the seventies and eighties, the black secondary figure almost always dies - an instance of non-linguistic patterning of plots. These codes we call semiotic, and they are at the basis of any communicative process. In fact, they have other wider uses than their communicative one. Semiotic codes are the means by which we make sense of reality, and in this sense literature, language, and other semiotic activities can be related to psychology, to the theories of perception and thought. For the moment, however, we will concentrate on literature and consider it in its communicative aspect. Literature is a particular kind of discursive activity, a part of the communicative processes carried out in society.

We will analyse now the structure of communication, the basic elements which are involved in any communicative activity. This we may apply to ordinary conversation, to literature, to a classroom lecture, or to any other discursive activity. We are going to compare two alternative versions of the communicative situation. The difference between these two versions should remind us that theories do not reflect an objective, unchangeable truth. Rather, they are linguistic constructs, tools we use to understand reality and give it a manageable shape for some specific purpose. All theories need not be equally explicit or exhaustive. Theories are not "real": they are versions of reality. Our first version of the communicative process, is by Karl Bühler. ${ }^{1}$ In this view, any sign has a threefold value, and each is related to a different function of language. In its relation to its meaning or its referent (the objects and relationships it signifies or refers to) the sign is a symbol that has a representative function. When we consider its relation to the sender, we study the sign as a symptom with an expressive function. When we see the sign in its relation to the receiver, we are seeing it as a signal with an appellative function. Figure 1 overleaf represents Bühler's view of the communicative sign.

1 Karl Bühler, Sprachtheorie. Jena: Gustav Fischer, 1934. 


\section{Figure 1}

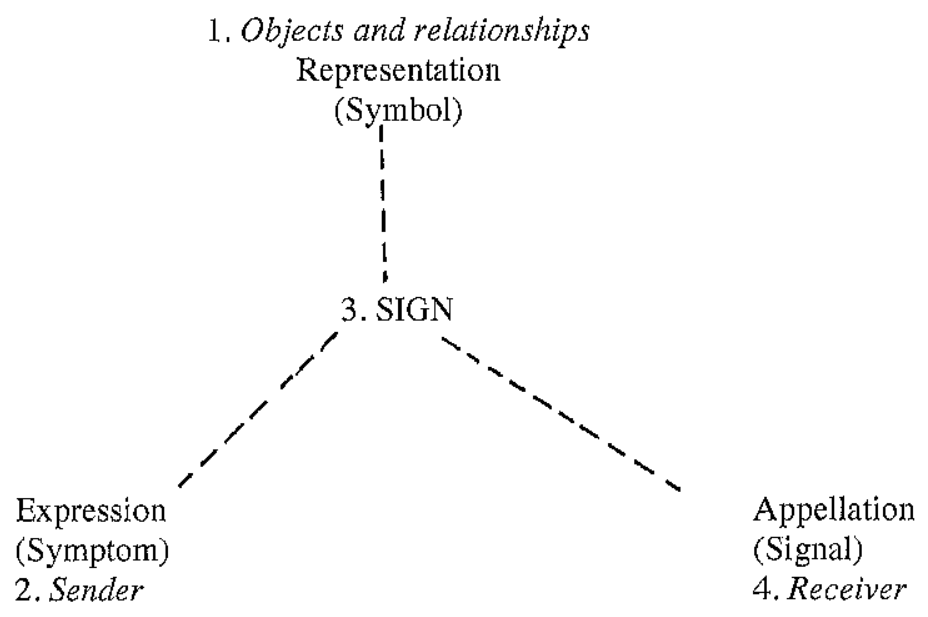

The second scheme we owe to Roman Jakobson. ${ }^{2}$ Jakobson distinguishes more elements in the communicative situation.

\section{Figure 2}

Context (or referent)

Addresser

Message Addressee

Contact

Code

An addresser delivers a message to an addressee. This always occurs in a context, to which the message refers. The message is a complex of signs which can be understood in relationship to a code (for instance, English). The contact includes the elements specific to this act of communication, such as the channel of transmission and the signs which ensure that communication is effectively taking place (e. g. the initial "hello" in a telephone conversation). As in Bühler's scheme, each element is related to a function of language (in italics):

\section{Figure 3:}

\section{Context (or referent): referential}

Addresser: Message: poetic Addressec: Conative

Contact: Phatic

Code: Metalingual

2 Roman Jakobson, "Linguistic and Poetics." In Style in Language, ed. T. A. Sebeok (Cambridge (MA): M. I. T. Press) 350-378. 
Jakobson's scheme derives from Bühler's, just as Bühler's derives from earlier ones. Bühler's scheme is less complete than Jakobson's, but they can be superposed with little contradiction. The relationship of these elements to the literary communicative situation can readily be seen:

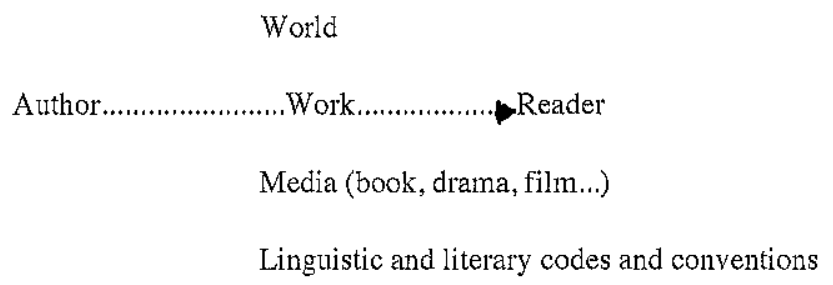

We will try to keep these schemes in mind when dealing with literature and the kind of attention literary theory devotes to literature.

We can intepret the rough outline of the history of literary criticism in terms of Jakobson's figure. Each period has tended to consider that the essence of the literary phenomenon, or the proper object of study of literary theory, is located in some element or other of the communicative situation. Of course all elements are present at all times in actual literary practice, and some degree of attention is given to all at all times, but somehow one of them reaches a prominence which makes it seem the really important one, the key to the secret of literature. From a semiotic point of view we must be concerned with all at all times, but we can't ignore the fact that different importance is given to them by the critics we will be studying.

- In classical and neoclassical criticism, the relationship between the literary sign and its object seems all-important: the representational element of literature is in the foreground. Literature is seen as a reflection or an imitation (mimesis ) of reality--classical and neoclassical theories of literature are often called mimetic.

- Medieval criticism, basically religious in nature, concentrates on the moral effects of the work on the audience.

- Romantic critics are mainly concerned with problems of creative inspiration, of expression, of sincerity. In our century, much psychoanalytical criticism is also concerned with this pole of the literary phenomenon: it studies the work as a symptom of the author's neuroses, obsessions, or fantasies. All these belong to the second element of Bühler's scheme, the area of the sender. Romantic theories of literature are often called expressive.

- The aestheticist theories of literature of the later nineteenth and the twentieth century (such as the New Criticism) are concerned with the study of the work in itself, with the message in our scheme considered not as a message but as an object existing and having value in its own right. This approach is often called immanentist or intrinsic .

- Structuralism is sometimes accused of immanentism, but this is an error. The structural criticism of literature which has developed from the 
30 s to our own days seeks to dissolve the study of the work into the study of the codes it is constituted or governed by. It is what in Jakobson's terms we would call a metalingual approach.

- To finish with, many contemporary approaches, such as readerresponse criticism and the Marxist, feminist, and deconstructive criticism of the $70 \mathrm{~s}$ and $80 \mathrm{~s}$ are concerned mainly with the fourth element of the communicative situation in Bühler's figure, the reader. Reader-response criticism and deconstruction often insist on the indeterminacy of meaning, the possibility of different interpretations, the active role of the reader in the construction of meaning, the existence of open-ended works, etc.

Excellent results may be obtained by focusing on the right aspect of literature at the right time, but nevertheless a literary critic ought to take into account all the elements which make up the literary communicative situation, and describe their complex interplay. The role attributed to each of the poles has changed from one epoch to another. For instance, as regards to the receiver, we have long had theories dealing with the intellectual, moral or emotional effects of literature, and these are still a major concern of Marxist and feminist critical schools. But the emphasis now falls on the theories of interpretation, which give the reader an active instead of a merely passive role. Similarly, in the pole of the sender of the author we may have theories which stress either creation or influence, the conscious or the unconscious activity of the author, etc.

We will now study the germ of all these theories in classical Greek criticism. The main lines of classical literary theory are mimetic--they are concerned mostly with the relationship between the work and reality. But in the best work of Plato or Aristotle we can find the elements of future interpretive and structural theories of literature. It is difficult at times to distinguish what is explicitly stated in a particular theory of criticism from what is merely implied, just as it was difficult to draw the line between literary theory and literary criticism. The merit of many a theorist is to make explicit what was implicit in an earlier one; in doing so, he will himself be implying more things than he is actually saying. With both activities he is contributing to the development of the theory of literature. It will be adequate, then, to begin our study of classical literary criticism with a knowledge of some current ideas about literature which were the background to the activity of the early theorists. These ideas are the equivalent to the mythical world-view from which philosophy emerged. Not surprisingly, many literary theorists of ancient Greece (and later too) are also philosophers. 


\section{Greek Origins of Literary Theory: Before Plato}

2.1. Myth and legend

2.2. Early poets as literary theorists

2.3. Early philosophers as literary theorists

\subsection{Myth and Legend}

In ancient Greece and up to the nineteenth century thought about literature is identified with thought about poetry. There is a clear concept of poetry, but there is not a concept of literature in the present-day sense of the word. Poetry is in Greece one among other arts, or rather several: in the late Alexandrian age, beside the muses of astronomy, dancing, and history, we find one muse assigned to each of the varieties of poetry: epic poetry, lyric poetry, comedy and pastoral poetry, tragedy, love poetry, and sacred songs. The muses were the attendants of the patron god of poetry, Apollo. There was also a close association between poetry and music. Lyric poetry, of course, was sung; and epic poetry was often chanted to musical accompaniment. Music was also a main feature in drama: Greek tragedies must have been closer to operas than to modern tragedies in this sense.

Some of the early thought about literature can be gathered from the tales about mythical poets-musicians, such as Orpheus and Amphion. ${ }^{3}$ Orpheus appears from the 6th century BC on as a musician whose lyre and voice bewitch Nature and fierce animals. Even the Sirens and the gods of the dead were placated by his song. Orpheus had the reputation of a teacher. Tradition wants that it was he who taught pederasty to the Thracians. In classical and Alexandrian times, Orphism developed into a specific mystery cult. The religious connotations of Orphism reach the sphere of poetry: we have then orphic hymns which exalt the harmony linking man to the macrocosm. The poet is regarded as an inspired being, the victim of a divine fury, which allows him an access to the vision of cosmic harmony.

The myth of Amphion is similar to that of Orpheus. He was a hero, the son of Zeus, who recieved from Hermes the gift of being able to play the lyre. Amphion built the walls of Thebes, making the stones move by themselves with the sound of his lyre. At least from Roman times on, the myths of Orpheus and Amphion were interpreted allegorically, as a mythical illustration of the civilising power of the arts.

But we needn't go as far as mythical figures to trace the notion of the poet as a teacher or a civiliser. The role played by Homeric poems in the

\footnotetext{
${ }^{3}$ For the Greek originso of literary theory see W. K. Wimsatt and Cleanth Brooks. Literary Criticism: A Short History (New York: Knopf; London: Routledge, 1957).
} 
educative sytem of ancient Greece rests upon this same conception of the poet being able to teach. Many would argue that Homer or Hesiod are themselves mythical figures, but that is of no consequence now. What is a fact is that the Iliad and the Odyssey, as well as Hesiod's works, were a kind of encyclopaedia of Greek culture. They contained the metaphysics, history, religion, geography and science of ancient Greece, and so it is hardly surprising that teaching should be one of the functions assigned to poetry from the first theoretical pronouncements. It was a function it was evidently carrying out at that time. Let us now examine the more explicit pronouncements of the poets themselves.

\subsection{Early Poets as Theorists}

\subsubsection{Homer}

At the very beginning of the Iliad we find an invocation to the Muse. This has been interpreted as a proof that Homer adheres to the theory that he, as a poet, is being driven by some supernatural force in the composition of his poem, that is, that he is being inspired in the original and proper sense of the word. Similar invocations can be found in the poems of Hesiod and Pindar. There is certainly a belief in inspiration at play here, but it is difficult to determine to what extent it is alive, which would imply strong religious connotations and a very definite theory of poetry, and to what extent it is already a well-worn rhetorical device which in itself bears little compromise to one theory of poetry or another. This is certainly the case in the Roman imitators of Homer. In the Homeric poems, aiodé, the gift of song, comes from the gods themselves: they can bestow it on mortals or snatch it away from them at their will.

At other points in the poems, Homer adds two other necessary qualities that the good bard must possess. The first, we have said, is inspiration, which seems to be concerned mainly with a knowledge of the facts of the story. The second is finding the right words, and the third is a pleasant voice. These requirements are more or less implicit here and there in the Homeric poems, so it is perhaps too rash to trace back to Homer the dichotomy form / content, or the classical rhetorical distinction between inventio, elocutio and actio . Roman critics like Cicero or Quintilian attributed to Homer the origins of the science of rhetoric. Odysseus, Nestor and Menelaus were supposed by them to be living examples of the three styles of rhetoric: high, medium, and plain. According to our own principles, however, Cicero and Quintilian were trying here to provide an illustrious origin to their own theories on rhetoric. Homer did distinguish the styles in which each of his character speaks, but it is a practical (or literary) and not a theoretical distinction. 
At one point, however, Homer makes an specific aesthetic judgement: he praises Achilles' shield for its realism, and goes on to describe all the scenes depicted in that shield (Iliad XVIII). Homer seems to share the general reverence for pictorial accuracy that we find in other Greek tales about artists--a stress, then, on the mimetic or referential function of art.

In sum, we can say that classical poetics is not born in the Homeric poems themselves, which illustrate contemporary, pre-theoretical views on poetry. However, we must acknowledge their significance they had for the Greeks as an encyclopaedic works on all aspects of life. And it was from the endless praise and commentary devoted to the Homeric canon that theoretical thought first appears in Greece. Theagenes (6th century BC) is the first Homeric scholar whose name is known to us. Apparently, his approach to Homer was a biographical one. The Iliad and the Odyssey are also among the favourite texts used by the great Greek critics, Plato, Aristotle and Longinus, in their theoretical works. Still later, philosophers of the Stoic school such as Zeno and Crates of Malos interpret the poems in an allegorical way, as illustrations of their own Stoic doctrines. They already speak of the "divine" Homer, and insist on their educational value. There are reactions to their views: Aristarchus of Samothrace develops a "realistic" interpretation of the poems opposed to any allegorical reading, and finds they are valuable mostly because of the pleasure they provide, and not because of what we what we would call their truth value or practical value. But all this is much later than Plato, and there are other poets beside Homer who have something to say on their craft.

\subsubsection{Hesiod}

Hesiod, too, is a mysterious figure, an encyclopaedic poet in an age of myth, before the arrival of such poets-philosophers as Empedocles or Parmenides. Indeed, we could grade a scale going down from myth into historical poets whose existence as personal individuals is more or less certain, and which would rank from Apollo, through Orpheus, Homer and Hesiod, to Empedocles. As is to be expected, Hesiod defends the value of poetry as teaching or instruction. However, he also speaks, like Homer, of a charming quality in poetry. We have then from the first an opposition between the useful and the merely delectable which will take one shape or another along the whole of the history of criticism: a long debate will oppose those who define poetry as instruction and those who see in it a form of enjoyment. Both theories, poetry-as-instruction and poetry-aspleasure, can be traced this far. To say at this point that poetry is instructive and not mere enjoyment means quite a different thing from maintaining this theory today. Those who say that poetry is instructive mean that the stories told by Homer and Hesiod are real, that they are history and religion as well as poetry. Both theories are present at least from Hesiod on. Generally, 
those who hold that poetry is instructive admit to its being delightful as well, but the opposite is not always the case. Until the early classical period, truth theories of poetry seem to have prevailed: this is a fact in the history of religion and historiography, with implications going well beyond the theory of poetry. However, in the classical period there were some strong reactions to these views. A whole new spirit, that of philosophy, is trying to fight the traditional myths. In spite of his having composed several literary works himself, Solon affirmed that poets lie a lot. This is the key statement of the second phase of Greek thought on literature, of which Plato is the main figure.

\subsubsection{Aristophanes (5th-4th centuries BC).}

We can find in the comedies of Aristophanes, a contemporary of Socrates, some statements on poetry similar to those already seen. For instance, we may look for them in the parabasis of the comedies, which is a choral piece in the middle of the work where the author makes the fiction pause and speaks directly to the public through the chorus, commenting on some current issue. In the parabasis of Aristophanes' comedy Frogs, the chorus invokes the muse to preside its performance, and to infuse delight to the words. The choregus begins his first speech with these words: "It is proper for the sacred chorus to be useful to the city with his counsels and his teachings." He then goes on to expound Aristophanes' political views to the audience, giving practical advice on how to deal with specific political issues and leaders. It is hardly surprising that the Old Comedy, deeply satirical and involved with contemporary events, should represent itself as a form of social and political action. On the other hand, the invocation to the muses in this text strikes us as already highly conventional.

But there are even more interesting theoretical views in Frogs, which can be considered as Aristophanes' poetic manifesto. The action takes place in Hell, and it involves an effeminate Dionysus who judges the relative merits of Aeschylus, holding at that time the throne as the best tragedian of Hell, and Euripides, who has just died and is challenging his rights. It is clear that Aristophanes has some definite views on the merits of each tragedian, for Euripides is abjectly defeated, and Sophocles occupies the throne while Aeschylus returns in triumph to a second life in the world above. What is most significant here is that the play is already dealing with a parody of critical procedures. Parodies make sense only if the thing parodied is well known to the public. The fact that this kind of parody could be presented successfuly onstage shows the interest arisen by such critical evaluations of plays, in the form of literary contests. It was 
customary in Greece to hold theatrical performances during the religious festivals. In fact, the origins of both tragedy and comedy can ultimately be traced to religious ceremonies. There were competitions between plays, and a prize was given every year to the best tragedy and the best comedy. Here is a fragment of Frogs which satirizes the critical procedures of the age:

Xanthias - So, the contest is going to take place?

Servant - Yes, by Zeus, in a short while. The battle will start right here. Their poetry is going to be weighed on the scales.

Xanthias - What! Is the tragedy going to be weighed with all rigour?

Servant - They will bring rulers, and squares to measure the verses, and quadrilateral molds ... and diameters and wedges. For Euripides says that tragedies must be checked line by line.

It is difficult to deduce from such a parody which were the actual criteria used in judging the value of a play, but there is certainly a rejection of the artificial and finicky procedures and rules used by some critics--in Frogs we witness the first critique of criticism.

As to the aim of poetry, Euripides declares in the play that poets are to be admired for their wit and their teaching, and also because they make men better. But his own tragedies are found to be at fault according to these rules, and in the end it is Aeschylus who is to return to the world above to save the city with his good counsel and to instruct the fools. The contest between the poets is not however much concerned with such weighty questions. For the most part, one poets upbraids the other because of his faults of thought and style as they show in small quotations from their poems which are used as touchstones. So we might add "skill in the craft" as a further condition required of a good poet by Aristophanes. We have here again the old pair "to teach" versus "to delight." Euripides is found to be too effeminate, finicky and at times immoral, while Aeschylus is found to be manly, violent and passionate, he is always shouting "like an oak on fire." Nevertheless, from the discussion we see that Aristophanes is also aware of the defects of Aeschylus and the merits of Euripides--and Aristophanes is thoroughly acquainted with the works of both of them. There is no talk of inspiration in the poets' contest. Dionysus speaks of the craft of the poets, and he purports that it can be weighed just "like cheese." In spite of the satire, the public and the judges of the times of Aristophanes, and Aristophanes himself, seem to share that view to some extent. We can imagine the surprisingly comical effect that Frogs must have had on its audience, when it located in Hell a satire of the kind of judgement the play itself was undergoing as it was being performed. Indeed, this comedy won the first prize in the year $405 \mathrm{BC}$. 


\subsection{Early Philosophers as Theorists of Literature}

We have already mentioned Solon's contention against literature--that poets are liars, or that poets lie too much. Xenophanes, Parmenides and Heraclitus are reported by Plato to have attacked Homeric theories of inspiration. They also oppose the notion of the poet being a wise man or a prophet. They probably believed the poet to be but the spokesman of dóxa or vulgar opinion: only philosophers can see through dóxa and understand reality.

Democritus, on the other hand, defends the theory of inspiration: he believes that the poet is a divine madman. We shall find this notion again in Plato and in many romantic theories of poetry.

Pythagoras, or rather the Pythagoreans, for Pythagoras himself is a shadowy figure, developed a whole theory of reality which foreshadows Platonism. Number is thought to be the basis of the universe. All things could in theory be reduced to numerical relationships, that is, the structure of reality can be given a mathematical formulation. The Pythagoreans made some substantial advances in mathematics, and also in the theory of music. They see music as one clear instance of the numerical structure of reality, and the mathematical study of music can be traced up to them. Pythagorism developed into a kind of aristocratic religion, a cult of small self-enclosed groups pervaded with secrecy and strange rituals. Music had an important part in that religion. They believed it had positive effects on the soul, something between therapeutic and ethical. Just as the world is number, harmony is a mimesis of that numerical structure. We could also say that the universe is harmony. The human soul, too, is a kind of harmony, and music can restore it whenever it is out of tune with the whole. The notion of mimesis is an important one, as is that of the psychological effects of music. We will find similar ideas later in Plato, Aristotle and Plotinus.

The sophists (5th century BC) seem to be responsible for the origins of systematic work on poetics and rhetoric. According to Stephen Halliwell, "the idea of a specialised discursive theory of poetic standards, or of communicable techniques of judgement, was a new phenomenon in the fifth century, and in this general respect, Aristotle was heir to the sophists." ${ }^{4}$ Many sophistic treatises on poetry and rhetoric must have been known to Aristotle, thought they have since been lost. There remain only scattered fragments and references to their work. Sophistic teachings were prescriptive: their aim was to teach how to speak and write successfully. Some of their work on linguistics is also relevant to literature.

$4 \quad$ Stephen Halliwell, Aristotle's Poetics (London: Duckworth, 1986) 8. 
The sophist Gorgias answers to those philosophers who speak of poets as a kind of liars. He says that poetry is a form of deception all right, but that the deceived is wiser than the undeceived. This is the first instance of a theoretical basis for a theory of fiction which goes beyond the question of the sincerity of the poet or the historical truth of poetry. In another fragment, Gorgias defines poetry as "discourse subject to rhythmical measure." It is discourse, language, but a special kind of language. The sophists point out that prose and poetry are not so far apart as they seem to be. They find that prose language, too, can be embellished with figures. They speak of two kinds of embellishment: gnomology, or embellishment throught the use of maxims, and eikonology, or embellishment of discourse through the use of images. There are several kinds of images, and later students of rhetoric will inherit and develop the achievements of the sophists in studying the figures of speech and thought.

Protagoras, best known for his saying that man is the measure of everything, classifies for the first time what we might call the functions of language, or, from another perspective, the kinds of speech acts. He calls them "grounds of discourses," and says that there are four: request, question, answer, order. He even applies them in a somewhat fastidious way to literature when he criticises Homer, after all a mere mortal, for giving orders to the muse in the invocation of the Iliad. Later sophists will propose different classifications of the kinds of discourses, distinguishing up to seven types of discourse. We notice that poetry, literature or fiction are not considered to be a different type of discourse in these classifications, and they are considered to be analysable with the same tools as the other uses of language. 